\title{
Quality of Knowledge Technology, Returns to Production Technology and Economic Development $^{\alpha}$
}

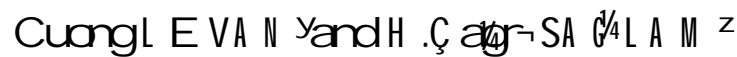

November 2, 2001

\begin{abstract}
A bstract
Presenting a discrete time version of the Romer (1986) model, this paper analyzes optimal paths in a one-sector growth model when the technology is not convex. We prove that for a given quality of knowledge technology, the countries could take-ox if their initial stock of capital are above a critical leve; otherwise they could face a povertytrap. We show that for an economy which wants to takeos by means of knowledge technology requires three factors: large amount of initial knowledge, small ..xed costs and a good quality of knowledge technology.
\end{abstract}

K eywords: Optimal growth, optimal path, valuefunction, povertytrap, increasing returns.

J ournal of Economic Literature : C61, 012, O32, 041.

\footnotetext{
${ }^{x}$ We thank Raouf Boucekkine for comments and suggestions. The second author has been supported by a grant "Actions Recherches Concertées" of the Ministry of the Belgian French Speaking Community.

${ }^{y}$ CERMSEM, UMR 8095 CNRS, University of Paris I, Maison des Sciences Economiques, 106-112 Boulevard de I'Hôpital, 75647 Paris Cedex 13, France. E-mail: Cuong.LeVan@univ-parisl.fr

${ }^{2}$ IRES, Université Catholique de Louvain, Place Montesquieu 3, 1348 Louvain-laNeuve, Belgium. E-mail: saglam@ires.ucl.ac.be
} 


\section{Introduction}

Convex structures of the technology and prefences have played an important role in economic analysis of optimal onesector growth models. They guarantee that the sequence of optimal stocks moves monotonically towards a unique steady state. (as in Cass (1965) and Koopmans (1965)). In these models, per-capita output should converge to a steady state due to the assumption of diminishing returns to per-capita capital in the production of per-capita output. However these studies were unable to explain the nonconvergence of countries whose potential causes could be the dixerent time preferences, technologies, demographies, market structures or economic policies.

In a mode of endogenous technological change in which the knowledge accumulated by the agents is the basic form of capital, Romer (1986) relaxing this usual assumption of diminishing returns showed that per-capita output can grow without bound and the level of per-capita output accross dixerent countries need not converge. In this analysis, new technology created by a single .r.rm which has a positive external exect on the other .r.rms is assumed to be the product of a research technology that exhibits diminishing returns. Thus, whereas production as a function of the ..rm exhibits diminishing returns, production as a function of the stock of knowledge in the economy is assumed to exhibit increasing returns.

On the other hand, Majumdar and Mitra (1982), Dechert and Nishimura (1983) analyzed an optimal growth model with a non-convex technology. Their key result was that the sequence of capital stocks is necessarily monotonic and under some assumptions they exhibit a poverty trap. Extending the analysis to an open country, Askenazy and Le Van (1999) in a continous time framework and Dimaria and Le Van (2001) in a discrete time framework also showed that if the debt constraint is hard, it could be optimal for a poor country to collapse while a rich country to converge to a high level of steady state.

In this paper, following LeVan, Morhaim and Dimaria (2001), we present a discrete time version of the Romer (1986) model and relax a fundamental hypothesis: nonconcavity of the production function. We analyze the case of a developing country with a production technology that exhibits linear production-capital ratio at the early stages of industrialization. Then for higher capital stodks, the production function becomes concave as in the case of a developed country. We prove the existence of solutions to the socialplanner problem and characterize the properties of the optimal paths. We show that a for a given quality of knowledge technology, the countries could 
takeox if their initial stock of capital are above a critical level; otherwise they could face a poverty-trap. We show that even a developed country may face a poverty-trap if endowed with a low quality of knowledge technology. Between two countries with the same production function and the same level of initial capital stock, when one faces a poverty-trap, the other could takeox if it is endowed with a higher quality of knowledge technology. We show that the dixerences in the quality of knowledgetechnology between countries can provide an explanation for the non-convergence of the countries.

The paper is organized as follows. In Section 2, presenting the model and its assumptions, westudy theexistence of solutions to the social-planner problem and analyze the properties and the convergence of optimal paths. Finally, Section 3 concludes.

\section{The In..nite-Horizon Growth M odel}

We consider a closed economy in which the preferences of the $\mathrm{S}$ identical consumers are globally represented by a strictly concave utility function of consumption, $\mathrm{u}(\mathrm{c})$ : The assumption is that:

(U1) $\quad u(c)$ is twice continously dixerentiable, $u^{9}(c)>0$; $u^{0}(c)<$ $0 ; 8 c>0$ and $u(0)=0 ; u^{9}(0)=+1$ :

Theinstantaneous production of output for a ..rm is given by $\mathrm{F}\left(\mathrm{k}_{\mathrm{t}} ; \mathrm{K}_{\mathrm{t}} ; \mathrm{X}_{\mathrm{t}}\right)$; which depends on the .r.rm speci..c knowledge $\left(\mathrm{k}_{\mathrm{t}}\right)$, the aggregate knowledge $\left(\mathrm{K}_{\mathrm{t}}\right)$, and the level of all other factors such as physical capital, labour, etc. To simplify and to have per-..rm and per-capita values coincide, we restrict our attention to an equilibrium in which the number of ..r.ms and the number of consumers are equal by assuming that $\mathrm{S}=\mathrm{N}=1$ : Following Romer (1986) and Le Van, Morhaim and Dimaria (2001), we assume that the additional factors are ..xed in supply so that the optimal solution for $x$ is $\bar{x}$. Dropping $x$ from the production function, let $f ; h$ and $F$ be:

$$
\begin{gathered}
F(k ; K ; \bar{x})=f(k) h(K) \\
F(k):=F(k ; k ; \bar{x})=f(k) h(k):
\end{gathered}
$$

We consider two cases:

i) a developed country where the production function is concave:

$$
\begin{aligned}
& \left.f(k)=k^{1} ; 12\right] 0 ; 1[; \\
& h(k)=k^{1 / 2}, 1 / 2>0
\end{aligned}
$$


ii) a developing country where the production function is a linear function in an initial phase and concave afterwards:

$$
\begin{aligned}
& f(k)=f_{A+k} A+k \cdot \bar{k} ; k, \bar{k} \text { and } \\
& h(k)=k^{1 / 2}, 1 / 2>0
\end{aligned}
$$

with $\pm_{\mathrm{i}}{ }^{1} \overline{\mathrm{K}}^{1} \mathrm{i}^{1}<0 \xi 0< \pm<1 ; 0<{ }^{1}<1$ and $1<1,+1 / 2$ Note that $\mathrm{A}<0$ as $A= \pm \bar{k}_{i} \bar{k}^{1}=\bar{k} \pm_{i} \bar{k}^{1}{ }^{1} \quad<\bar{k}{ }^{1} \bar{k}^{1}{ }^{1}{ }_{i} \bar{k}^{1}{ }^{1}=\bar{k}^{1}\left({ }^{1} i 1\right)<0$ :

The in $\neq$ uence of the ..xed costs on the output can be measured through two indicators which are $\bar{k}$ and \pm The .xed costs are more important if $\bar{k}$ increases or/and if \pm decreases.

Investing an amount $I_{t}$ of forgoing consumption, a .r.m with a current stock of private knowledge $k_{t}$ produces additional knowledge which induces a rate of growth

$$
k_{t+1} ; k_{t}=G\left(I_{t} ; k_{t}\right)
$$

Assume that:

(G 1) G is concave and homogenous of degree one. Then:

$$
\frac{\mathrm{k}_{\mathrm{t}+1} \mathrm{i} \mathrm{k}_{\mathrm{t}}}{\mathrm{k}_{\mathrm{t}}}=\mathrm{G}\left(\frac{\mathrm{l}_{\mathrm{t}}}{\mathrm{k}_{\mathrm{t}}} ; 1\right)=\mathrm{g}\left(\frac{\mathrm{l}_{\mathrm{t}}}{\mathrm{k}_{\mathrm{t}}}\right)
$$

(G3)

$$
g(0)=0 ; g^{9}(0)=\frac{1}{2}<+1
$$

For an arbitrary path $\mathrm{K}$, the social optimization problem maximizes the utility of a representative consumer subject to the technology implied by the path $\mathrm{K}$.

$$
\begin{array}{ll} 
& \text { M aximize }{ }^{X^{1}}-t_{t} u\left(c_{t}\right) \\
\text { s:t: } \quad 0 \cdot \frac{k_{t+1} k_{t}}{k_{t}} \cdot g\left(\frac{F\left(k_{t}\right) i c_{t}}{k_{t}}\right) \\
k_{0}>0 \text {; given: }
\end{array}
$$

Note that in social optimization problem, the production function exhibits an initial phase of increasing returns and a second phase with de- 
creasing returns. Note also that this problem is equivalent to:

$$
\begin{aligned}
\text { Maximize } & { }^{X^{1}}-t_{t} u\left(F\left(k_{t}\right) i k_{t}{ }^{\circ}\left(\frac{k_{t+1} i k_{t}}{k_{t}}\right)\right) \\
\text { s:t: } k_{t} \cdot & k_{t+1} \cdot k_{t} g\left(\frac{F\left(k_{t}\right)}{k_{t}}\right)+k_{t} \\
& k_{0}>0 ; \text { given: }
\end{aligned}
$$

where $^{\circ}:=$ gi $^{1}$ :

Following from (G3), note that $k_{t} \cdot k_{t+1} \cdot k_{t}(1+\mathbb{B})$. Then we have, $k_{t} \cdot k_{0}(1+\circledast)^{t}$ inducing that, $F\left(k_{t}\right) \cdot F\left(k_{0}(1+\mathbb{a})^{t}\right) \cdot-k_{0}^{1 / 2+1}(1+\mathbb{e})^{(1 / 2+1)^{-q}}$ : In what follows we assume that:

(P 1) $\quad 0_{3}<^{-}<1$ and $^{-}(1+\mathbb{B})^{(1 / 41)}<1$ :

Denoting $g \frac{F(\bar{k})}{\bar{k}}$ by $g<\mathbb{R}$, we also assume that:

(P 2) $\quad{ }^{\circ}(x)=$, $x$; when $x 2[0 ; \bar{g}]$.

Note that at zero an increase of one percent in the amount of investment induces an increase of $1=$, percent in the stock of private knowledge which enables us to interpret that $1=$ refects the quality of the knowledge technology.

\subsection{Existence of a Solution}

A sequence $R=\left(\mathrm{k}_{\mathrm{t}}\right)_{\mathrm{t}}$ is called feasible from $\mathrm{k}_{0}$ if it satis. es the constraints of the social optimization problem:

$$
8 t ; k_{0} \cdot k_{t+1} \cdot k_{t} g^{\mu}{\frac{F\left(k_{t}\right)}{k_{t}}}^{9}+k_{t}
$$

In this section, we. r.st provethat every feasible sequence from $k_{0}$ belongs to a compact set for the product topology; second we show that the objective function is continous for this topology. Existence of solutions follows from these results.

\subsubsection{Compactness}

Let $R$ be a feasible path from $k_{0}$. Then by assumption (G3), for every $t$ :

$$
k_{t} \cdot k_{t+1} \cdot k_{t} g\left(\frac{F\left(k_{t}\right)}{k_{t}}\right)+k_{t} \cdot(1+\circledast) k_{t}
$$


so, $k_{t} \cdot\left(1+\circledR{ }^{t} k_{0}\right.$; that is:

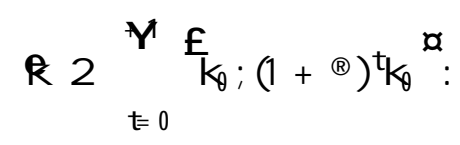

Thus, $R$ belongs to a compact set for the topology. Since $g$ and $F$ are continous, the feasible set from $\mathrm{k}_{0}$ is compact for the product topology.

\subsubsection{Continuity of the objective function}

The objective function is:

$$
U: R_{i} !_{t=0}^{* 1}-t_{u}^{\mu} F\left(k_{t}\right) i k_{t}^{\circ}{ }^{\mu} \frac{k_{t+1} k_{t}}{k_{t}}{ }^{\text {ๆ }} \text { : }
$$

By means of the proof availablein LeVan, Morhaim and Dimaria (2001), we know that $U$ is continous for the product topology.

Thus, with the objective function being continous and the feasible path set being compact for the product topology, the problem has a solution.

\subsection{Value function, Bellman equation}

Let $\mathrm{V}\left(\mathrm{k}_{0}\right)$ denote the value function of the social optimization problem. It is clear that the value function veri..es the Bellman equation:

$$
V\left(k_{0}\right)=\max _{k_{0} \cdot y \cdot k_{0} g \frac{F\left(k_{0}\right)}{k_{0}}+k_{0}} u^{1 / 2 \mu} F\left(k_{0}\right) i_{k_{0}}{ }^{\mu} \frac{y_{i} k_{0}}{k_{0}}{ }^{\text {१ी }}+{ }^{-} V(y)^{3 / 4}
$$

$\mathrm{V}$ is the unique continous solution to Bellman equation. Let

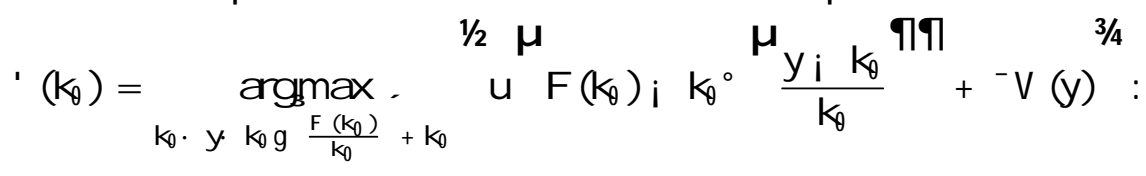

By the maximum theorem, ' is upper semi-continous.

\subsection{Properties and convergence of optimal paths}

In this section we derive some properties of optimal paths. First, we show the non-nullity of optimal consumption and capital. Second, we prove that there exists a critical value $k_{c}$ which may be interpreted as the "top" of the poverty trap. 
Lemma $1 \frac{F(k)}{k_{3}}$ and $F q(k)$ are increasing functions in $[0 ; \bar{k}[$ and $] \bar{k} ;+1$ [:

Proof. i) ${ }^{\frac{F}{k}(k)}{ }^{0}=\frac{1}{k^{2}}[F q(k) k$ i $F(k)]$ : What follows from the de.nition of $F(k)$ is that:

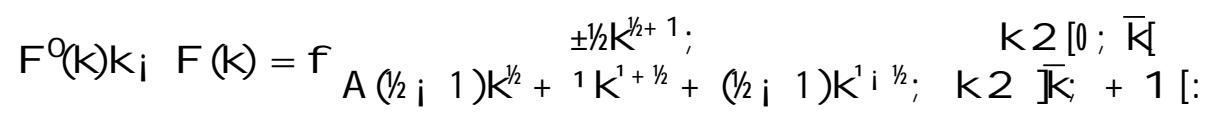

There are two cases to be checked when $\mathrm{k} 2] \mathrm{k} ;+1[$ :

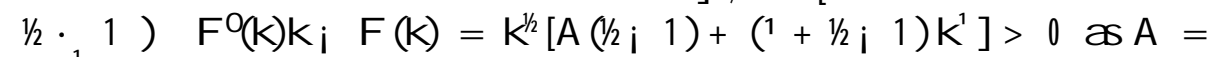
$\pm \bar{k} i \bar{k}^{1}<0$ and

$1 / 2>1) \quad F(k) k_{i} F(k)=k^{1 / 2}\left[k^{1}+(1 / 2 i 1)\left(k^{1}+A\right)\right]>0$ as $k^{1}+A$, $\overline{\mathrm{K}}^{1}+\mathrm{A}=\overline{\mathrm{k}}$ : Thus $\frac{\mathrm{F}(\mathrm{k})}{\mathrm{k}}$ is an increasing function in $[0 ; \overline{\mathrm{k}}[$ and $] \overline{\mathrm{k}} ;+1[$ :

ii)

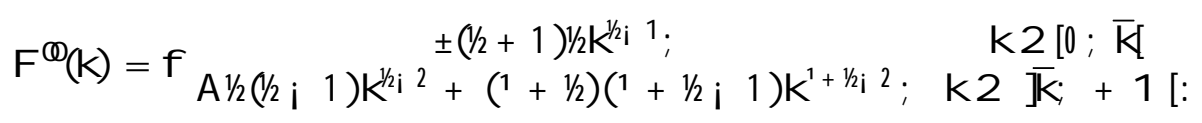

It is clear that $\mathrm{F} \widetilde{q}_{(\mathrm{k})}>0$ for $\mathrm{k} 2[0 ; \overline{\mathrm{k}}[:$ There are two cases to be checked when $\mathrm{k} 2] \overline{\mathrm{k}} ;+1[$ :

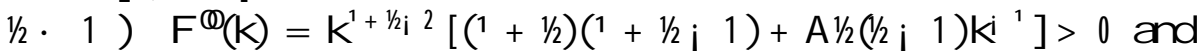

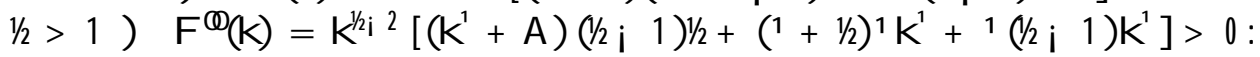
Thus, $\mathrm{F} q(\mathrm{k})$ is an increasing function in $[0 ; \mathrm{k}$ [and $] \overline{\mathrm{k}} ;+\underset{3}{1}[$.

Lemma $2 \frac{\Theta^{2} W(k ; y)}{(\alpha(@)}>0$ where $W(k ; y)=u \quad F(k)$ i $k^{\circ} \frac{y_{i} k}{k}$.

P roof. See Le Van, Morhaim and Dimaria (2001).

Let $B(x)=x g\left(\frac{F(x)}{x}\right)+x$ :

Lemma 3 Our optimal growth model can be written as:

$$
\begin{gathered}
\max ^{X^{A}=0}-{ }^{t} W\left(x_{t} ; x_{t+1}\right) \\
\text { s:t: } x_{t} \cdot x_{t+1} \cdot B\left(x_{t}\right) \\
x_{0}>0 \text { is given }
\end{gathered}
$$

which leads to the value function verifying the Bellman equation given as

$$
V\left(x_{0}\right)=\max _{x_{0} \cdot y \cdot B\left(x_{0}\right)}\left[W\left(x_{0} ; y\right)+{ }^{-} V(y)\right]
$$

where $B$ is an increasing function. Let $f x_{t} g$ and $f x_{t}^{0} g$ be optimal paths starting from $x_{0}$ and $x_{0}^{0}$ respectively. If $x_{0}<x_{0}^{0}$ then $x_{1} \cdot x_{1}^{0}$ : 
P roof. The result comes from the fact that $\frac{\varrho^{2} w(k ; y)}{\text { बk@ }}>0$ : Se Benhabib and Nishimura (1985).

Proposition 1 If $\mathrm{fk}_{\mathrm{t}} ; \mathrm{c}_{\mathrm{t}} \mathrm{g}$ is an optimal path from $\mathrm{k}_{03}>0$; then $8 \mathrm{t}, 0$ $k_{t}>0 ; c_{t}>0$ : Similarly if $k_{1} 2^{\prime}\left(k_{0}\right)$ then $F\left(k_{0}\right) i k_{0}^{\circ} \frac{k_{1 i} k_{0}}{k_{0}}>0$ :

P roof. The proof is based on Inada condition of the utility function. See Le Van, Morhaim and Dimaria (2001).

Proposition 2 Let, $>0$ be given. There exists $k^{\infty}>0$ such that $8 k_{0}<$ $\mathrm{k}^{a} ; \mathrm{k}_{0}>0 ; 8 \mathrm{k}$ optimal from $\mathrm{k}_{0}$ then $\mathrm{k}_{\mathrm{t}}=\mathrm{k}_{0} ; 8 \mathrm{t}$ :

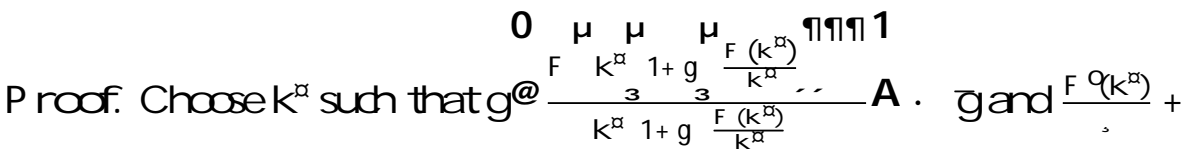
$(1+\mathbb{R})<\frac{1}{=}$ : Since $\frac{F(k)}{k}$ is increasing by Lemma 1 and $\lim _{k !} 0 \frac{F(k)}{k}=0$; such a $k^{\alpha}$ exists. Let for $k_{0}<k^{\alpha}$; there exists a strictly increasing optimal path. We have Euler equation given as :

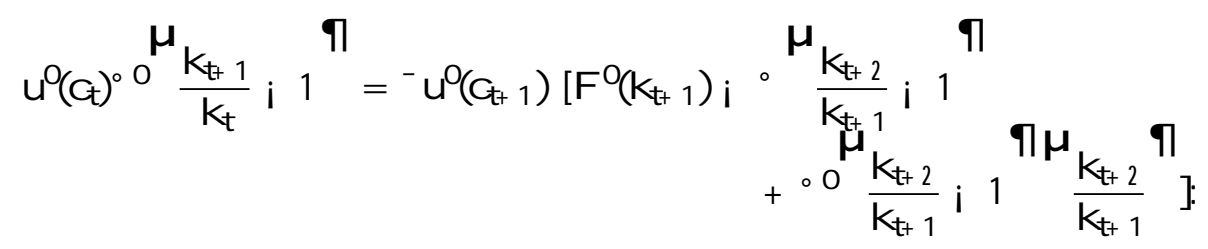

Our claim is that thereexists t such that $k_{t+1}<k^{\alpha}$ and $k_{t+2}, k^{\alpha}$ : If not, we have allways $k_{t}<k^{\infty}$; 8t: Then $k_{t} ! k_{s}, k_{0}>0$ and $c_{t} ! F\left(3 k_{s}\right)>0$ with

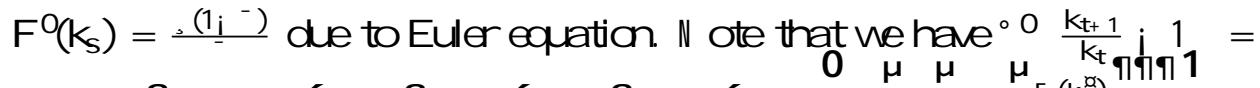

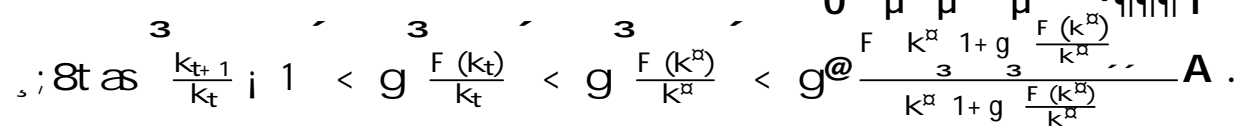
$\mathrm{g}$ and ${ }^{\circ}(\mathrm{x})=$, $\mathrm{x}$ for $\mathrm{x} 2[0 ; \mathrm{g}]$ according to Assumption (P2).

However, since $\mathrm{F}^{0}$ is increasing in $[0 ; \overline{\mathrm{k}}[$ and $] \overline{\mathrm{k}} ;+1$ [ by Lemma 1 and $\left.k_{s} \cdot k^{\alpha} ; F q\left(k_{s}\right) \cdot F q^{\infty}\right)<,\left(\underline{1}^{-}\right)$leads to a contradiction.

Hence there exists $t$ such that $k_{t+1}<k^{x}$ and $k_{t+2}, k^{x}$ : In what follows, consider a path $f k_{0}^{n} g$ converging to zero and let $T_{n}\left(k_{0}^{n}\right)$ be the point such that

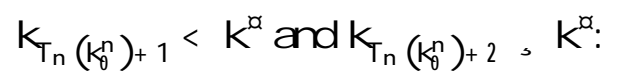


From $t=0$ to $T_{n}\left(k_{0}^{n}\right)+1$ we have :

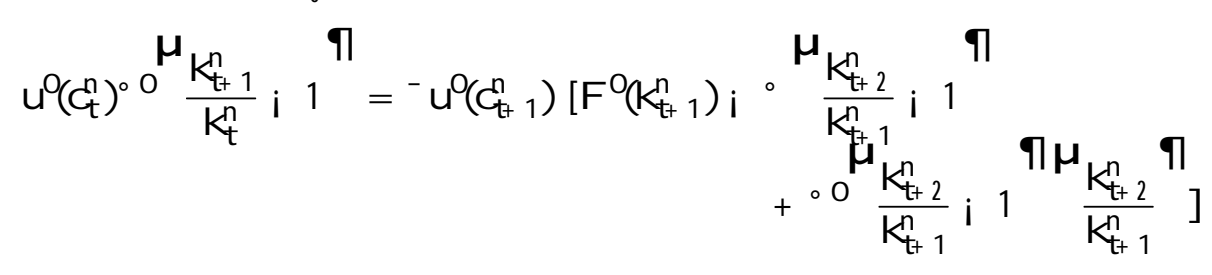

which reduces to

$$
u^{q}\left(c_{t}^{n}\right)=-u^{q}\left(c_{t+1}^{n}\right) \frac{F^{0} k_{t+1}^{n}}{\lrcorner}+(1+\AA) ;
$$

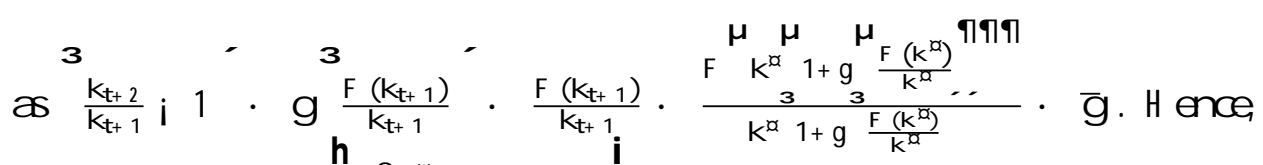

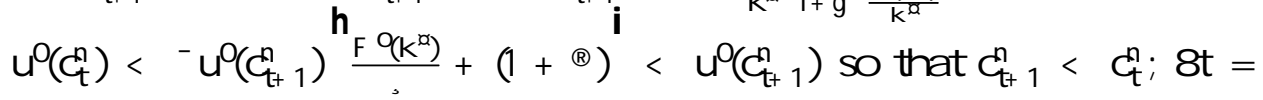
$0 ; \ldots ; T_{n}+1$ : Now letting $n ! 1 ; k_{T_{n}\left(k_{0}^{n}\right)+1}$ converges to $k \cdot k^{\mathbb{a}}$ and $k_{T_{n}}\left(k_{0}^{n}\right)+2$ converges to $R^{0}, k^{\natural}$ : By the upper semi-continuity of ' ; $R^{0} 2 R^{\prime} R_{3}$ : Sinçe $R>0$; from proposition $1, R^{0}>0$ : Then $C_{T\left(k_{0}^{n}\right)+1}^{n} !{ }_{3}^{F}(R)_{i}, R^{\circ} \frac{k_{0}^{0} k}{k}$. Following from Inada condition we have that $F\left(R_{i} \quad R^{\circ} \frac{k_{0} k_{k}}{R}>0\right.$ on the

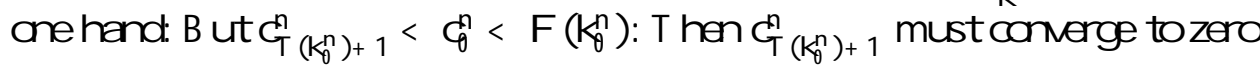
on the other hand: a contradiction. from $k_{0}$ :

Hence for $k_{0}$ small enough, $\left(k_{0} ; k_{0} ;:: k_{0}:::\right)$ is the unique optimal path

Proposition 3 Let, $>0$ be given. There exists $k^{\text {sad }}>0$ such that $8 k_{0}>$ $\mathrm{k}^{\mathrm{x} o \mathrm{a}} ; 8 \mathrm{R}$ optimal from $\mathrm{k}_{0}$ then $\mathrm{k}_{\mathrm{t}}<\mathrm{k}_{\mathrm{t}+1} ; 8 \mathrm{t}$ and $\mathrm{k}_{\mathrm{t}} !+1$ :

Proof. Choose $\mathrm{k}^{\mathrm{nax}}$ such that $\mathrm{F}^{0}\left(\mathrm{k}^{\mathrm{max}}\right) \frac{-}{\mathrm{Ii}_{\mathrm{i}}}=$, Our daim is that if $k_{0}>k^{n a x}$; then any optimal path is strictly increasing and grows without bound. In order to prove this, we will .r.st show that for any $k_{0}>k^{\infty 00}$, the path $R_{0}=\left(k_{0} ; k_{0} ;:: ; k_{0} ;::\right)$ is not optimal. Then we will show that any optimal path is strictly increasing and no optimal path from $k_{0}>k^{\text {ax }}$ converges to a steady state.

i) Consider the path $\beta_{11}=\left(k_{0} ; k_{0}+" ; k_{0}+" ;:: ; k_{0}+":::\right)$ that is feasible from $k_{0}: k_{0} \cdot k_{0}<k_{0} g \frac{F\left(k_{0}\right)}{k_{0}}+k_{0}$ : Since $k_{0} g \frac{F\left(k_{0}\right)}{k_{0}}>0$; there exists " $>0$ such that $k_{0}+" \cdot k_{0} g \frac{F\left(k_{0}\right)}{k_{0}}+k_{0}:$ Then for $k_{1}:=k_{0}+$ " and $k_{t}:=k_{1}$; 
8t. 1; we have $\mathrm{k}_{0} \cdot \mathrm{k}_{\frac{1}{3}} \cdot \mathrm{k}_{0} \mathrm{~g}^{3} \frac{\mathrm{F}\left(\mathrm{k}_{0}\right)^{\prime}}{\mathrm{k}_{0}}+\mathrm{k}_{0}$ and $\mathrm{k}_{1} \cdot \mathrm{k}_{1} \cdot \mathrm{k}_{1} \mathrm{~g}^{3} \frac{\mathrm{F}\left(\mathrm{k}_{1}\right)^{\prime}}{\mathrm{k}_{1}}+\mathrm{k}_{1}$ that is $k_{t} \cdot k_{t+1} \cdot k_{t} g \frac{F\left(k_{t}\right)}{k_{t}}+k_{t}$ : Thus there exists " $>0$ such that $R_{1}$ is feasible from $k_{0}$ : Now we will show that such a path increases the value of U :

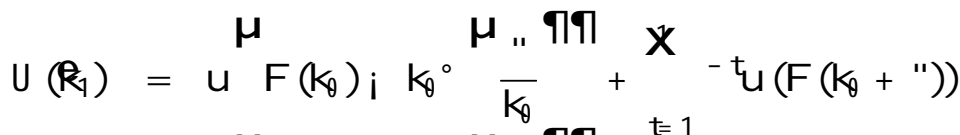

$$
\begin{aligned}
& \mu \quad \mu{ }_{\text {" }} \text { ๆ ๆ } t=1
\end{aligned}
$$

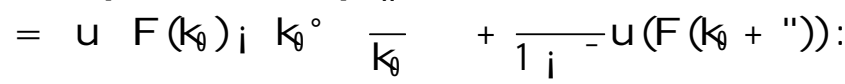

$$
\begin{aligned}
& \mathrm{U}\left(\mathrm{R}_{0}\right)=\mathrm{u}\left(\mathrm{F}\left(\mathrm{k}_{0}\right)\right)+\frac{-}{1_{\mathrm{i}}} \mathrm{u}\left(\mathrm{F}\left(\mathrm{k}_{0}\right)\right):
\end{aligned}
$$

Then,

$$
\begin{aligned}
& U\left(R_{1}\right) \text { i } U\left(R_{0}\right)=u^{\mu} F\left(k_{0}\right) \text { i } k_{0}^{\circ} \bar{k}^{\mu} \text { " वी } \text { i } u\left(F\left(k_{0}\right)\right)^{2} \\
& +\frac{-}{1_{i}}-\left[u\left(F\left(k_{0}+"\right)\right) \text { i } u\left(F\left(k_{0}\right)\right)\right]
\end{aligned}
$$

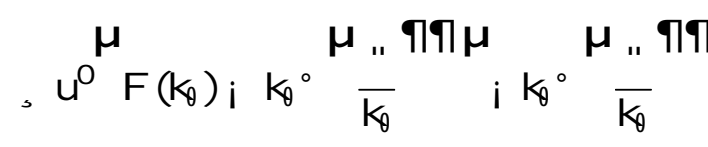

$$
\begin{aligned}
& +\frac{-}{1_{i}}-u^{0}\left(F\left(k_{0}+"\right)\right)\left(F\left(k_{0}+"\right) i F\left(k_{0}\right)\right)
\end{aligned}
$$

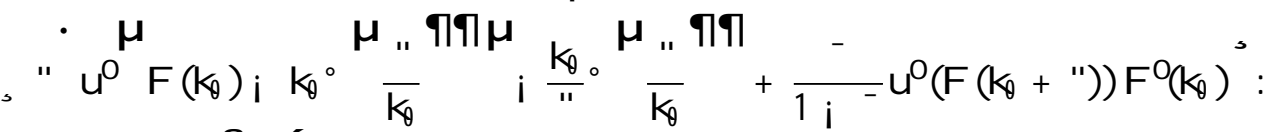

Since $\lim _{n !} \frac{k_{0}}{\|}{ }^{\circ} \frac{"}{k_{0}}=\circ q(0)=, F^{0}$ is increasing and $k_{0}>k^{\infty x}$, we have $\mathrm{F} q\left(\mathrm{k}_{0}\right)>$, $\frac{\left(\mathrm{li}^{-}\right)}{}$: Thus, there exists " > 0 such that $\mathrm{U}\left(R_{1}\right)$ i $U\left(R_{0}\right)>0$ concluding that $R_{0}$ is not optimal.

ii) If there were an optimal path such that $k_{1}=k_{0}$ then as the value function veri. .es the Bellman equation:

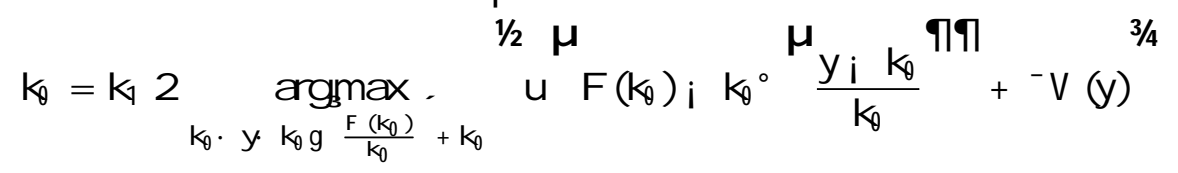

the path $R_{0}=\left(k_{0} ; k_{0} ;:: ; k_{0} ;::\right)$ would then be optimal which is impossible So necessarily, $k_{1}>k_{0}$ : Similarly what follows is that $8 t ; k_{t+1}>k_{t}$ : 
iii) Writing the Euler equation :

$$
\begin{aligned}
& i_{0} \circ \frac{k_{t+1} i k_{t}{ }^{\text {शी }}}{k_{t}} u^{\mu} F\left(k_{t}\right) i k_{t}{ }^{\mu} \frac{k_{t+1} i k_{t}}{k_{t}}+
\end{aligned}
$$

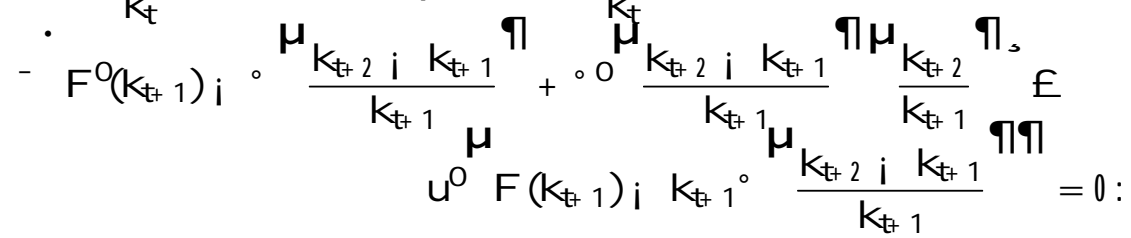

Since $k_{t}$ is strictly increasing, $\lim _{t ! 1} k_{t}$ exists. Suppose on the contrary that $k_{t}$ converges to $k_{s}<+1$ : Then we would have

$$
F^{q}\left(k_{s}\right) \frac{-}{1_{i}-}=
$$

But $\mathrm{F}_{+}^{0}\left(\mathrm{k}^{\mathrm{po}}\right) \frac{-}{\mathrm{1}_{\mathrm{i}}}=$, and $\mathrm{k}_{\mathrm{s}}>\mathrm{k}^{\mathrm{pod}}$ : a contradiction since $\mathrm{F}^{0}$ is increasing. So $k_{\mathrm{t}}$ diverges to +1 inducing that per-capita output grows without bound.

Proposition 4 Let $k^{\text {ax }}$ be de. ned by $\mathrm{F}^{0}\left(\mathrm{k}^{\mathrm{ax}}\right) \frac{-}{1_{\mathrm{i}}}=$, Let $\mathrm{k}_{0}>0$ : No optimal path from $k_{0} \in k^{\text {nax }}$ converges to $k^{\text {nax }}$ :

Proof. If $k_{0}>k^{\mathrm{kox}}$; from proposition 3 , any optimal path from $\mathrm{k}_{0}$ will converge to +1 : Consider the case where $k_{0}<k^{\text {nox }}$ : Let $f k_{t} g$ be an optimal path from $k_{0}$ and assume it converges to $k^{\text {pox }}$ : This optimal path must be increasing and bounded above by $k^{\text {max }}$. There exists $T_{0}$ such that 8t, $\mathrm{T}_{0} ; \frac{\mathrm{k}_{\mathrm{t}+1 \mathrm{i} \mathrm{k}_{t}}}{\mathrm{k}_{\mathrm{t}}} \cdot \mathrm{g}$ and hence ${ }^{\circ} \frac{\mathrm{k}_{\mathrm{t}+1 \mathrm{i} \mathrm{k}_{\mathrm{t}}}}{\mathrm{k}_{\mathrm{t}}}=\frac{\mathrm{k}_{\mathrm{t}+1 \mathrm{i} \mathrm{k}_{\mathrm{t}}}}{\mathrm{k}_{\mathrm{t}}}$ : The optimal consumption, for $t, T_{0}$ will be $c_{t}=F\left(k_{t}\right)+, k_{t} i, k_{t+1}$ : We also have,

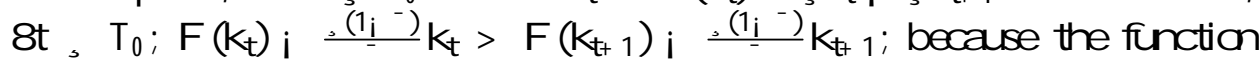
$F(k) i \frac{\left(1_{i}{ }^{-}\right)}{k} k$ is decreasing when $k$ is closeto $k^{\text {ax }}$ and $k<k^{\text {ax }}$ : Thefollowing inequality holds:

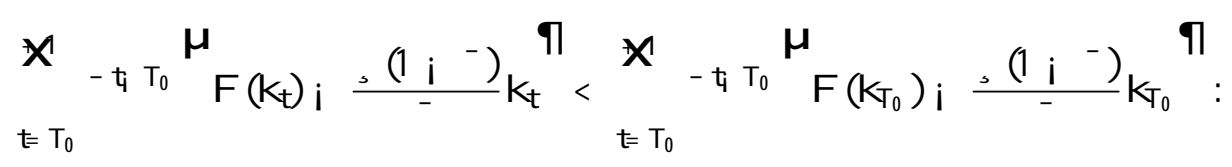

But,

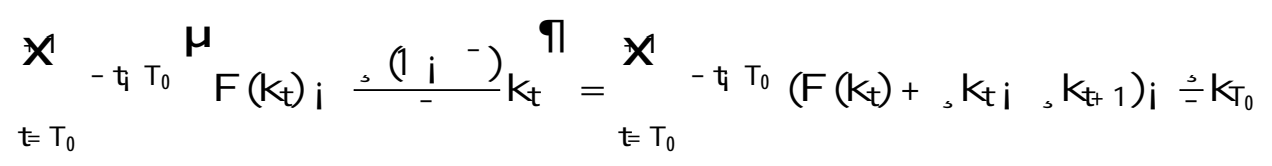


and

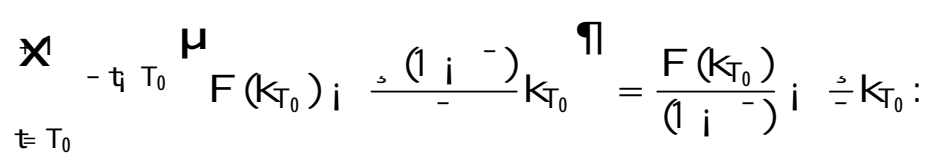

Thus,

$$
\mathbb{t}_{t=T_{0}}^{1}-t_{i} T_{0}\left(F\left(k_{t}\right)+, k_{t} i, k_{t+1}\right)<\frac{F\left(k_{T_{0}}\right)}{\left(1 i^{-}\right)}
$$

i.e.

$$
\mathbb{H}^{1}-\mathrm{t}_{\mathrm{i}} \mathrm{T}_{0} \mathrm{C}_{\mathrm{t}}<\frac{\mathrm{F}\left(\mathrm{k}_{\mathrm{T}_{0}}\right)}{\left(1 \mathrm{i}^{-}\right)}
$$

By J ensen's inequality, we have

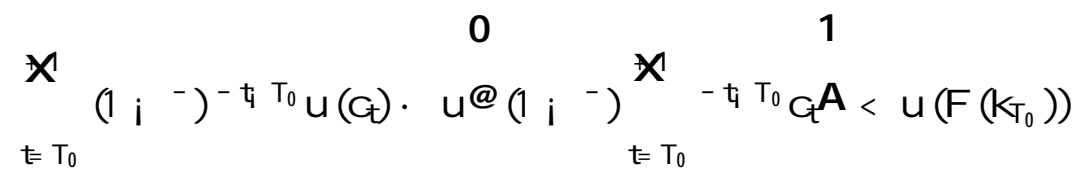

or

$$
x^{1}-t_{i} T_{0} u\left(c_{t}\right)<{ }_{t=T_{0}}^{*^{1}}-t_{i} T_{0} u\left(F\left(k_{T_{0}}\right)\right):
$$

This means that the utility of the stationary path $k_{t}=k_{T_{0}}$ for $t, T_{0}$ is better than the utility from $\mathrm{T}_{0}$ of the optimal path : a contradiction.

Theorem 1 Let, $>0$ be given. Then there exists $k_{c}$ such that $8 k_{0}<k_{c}$; any optimal path $R$ from $k_{0}$ will satisfy $k_{t}=k_{0} ; 8$ t and $8 k_{0}>k_{c}$; any optimal path $\mathrm{R}$ from $\mathrm{k}_{0}$ will satisfy $\mathrm{k}_{\mathrm{t}}<\mathrm{k}_{\mathrm{t}+1} ; 8 \mathrm{t}$; and $\mathrm{k}_{\mathrm{t}}$ ! +1 :

P roof. Let $k^{M}$ be the supremum of the $k_{\alpha}$ such that if $k_{0}<k_{\alpha}$ then any optimal path $R$ from $k_{0}$ will satisfy $k_{t}=k_{0} ; 8 t$ : Let $k^{m}$ be the in. mum of the $k_{\text {on }}$ such that if $k_{0}>k_{\text {ax }}$ then any optimal path $k$ from $k_{0}$ will converge to +1 : Our claim is that $k^{\mathrm{M}}=\mathrm{k}^{\mathrm{m}}$ : It is obvious that $\mathrm{k}^{\mathrm{M}} \cdot \mathrm{k}^{\mathrm{m}}$ : Suppose $\mathrm{k}^{\mathrm{M}}<\mathrm{k}^{\mathrm{m}}$ : Take $\mathrm{k}_{0}$ and $\mathrm{k}_{0}^{0}$ such that $\mathrm{k}^{\mathrm{M}}<\mathrm{k}_{0}<\mathrm{k}_{0}^{0}<\mathrm{k}^{\mathrm{m}}$ : From the very de. nition of $k^{\mathrm{M}}$ and $\mathrm{k}^{\mathrm{m}}$; there exists an optimal path $\mathrm{fk}_{\mathrm{t}} \mathrm{g}$ from $\mathrm{k}_{0}$ which is strictly increasing and an optimal path $\mathrm{f}_{\mathrm{t}}^{0} \mathrm{~g}$ from $\mathrm{k}_{0}^{0}$ which is stationary, i.e $\mathrm{k}_{\mathrm{t}}^{0}=\mathrm{k}_{0}^{0}$; 8t: By the increasingness property of the optimal policy, we have $\mathrm{k}_{\mathrm{t}} \cdot \mathrm{k}_{0}^{0}$; 8t: Hence $\mathrm{k}_{\mathrm{t}}$ ! $\mathrm{R}$ : It is easy to check that $\mathrm{F}^{0} \mathrm{R}=\frac{\left(\mathrm{l}_{\mathrm{i}}{ }^{-}\right)}{\mathrm{k}^{0}}$ and this contradicts proposition 4. Therefore $\mathrm{k}^{\mathrm{M}}=\mathrm{k}^{\mathrm{m}}$ : Posing $\mathrm{k}_{\mathrm{c}}=\mathrm{k}^{\mathrm{M}}=\mathrm{k}^{\mathrm{m}}$ ends the proof. 


\section{Concluding Remarks}

i) Let $k_{0}>0$ be given. By proposition 3 , if , is small enough then any optimal path from $\mathrm{k}_{0}$ will converge to +1 : In particular, the Romer model formalized in discrete timehorizon by LeVan, Morhaim and Dimaria (2001) is the limit case of our model by letting , ! 0 : Moreover, consider two countries with the same production technology and the same level of initial capital stock. By proposition 3, when one faces a poverty-trap, the other could take on if it is endowed with a higher quality of knowledge technology. That is to mention that the dixerences in the quality of knowledge technology between countries can provide an explanation for the non-convergence of the countries. have

ii) Consider the equality $\mathrm{F}^{0}\left(\mathrm{k}^{\mathrm{Dax}}\right) \frac{-}{1_{\mathrm{i}}}=$, and assume that $\mathrm{k}^{\mathrm{Dax}}>\overline{\mathrm{k}}$ :We

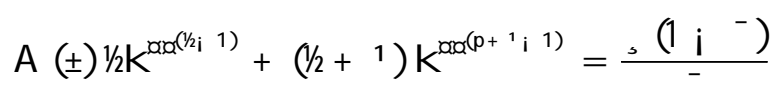

where $\mathrm{A}(\sharp)=\bar{k}_{\mathrm{i}} \overrightarrow{\mathrm{K}}^{1}$ : By dixerentiating with respect to \pm we obtain that

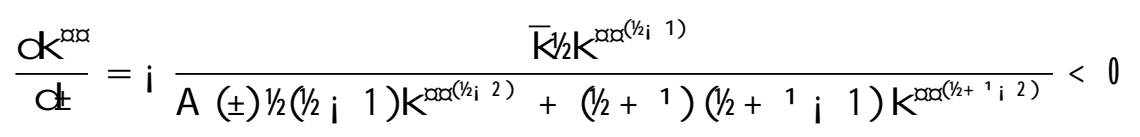

because, since $k^{\text {ax }}>\bar{k}$; the denominator is positive. One can condude that, given $k_{0}$; if the infuence of the ..xed costs diminishes (i.e \pm increases), the economy can take-ox.

Furthermore, by dixentiating the given equality $\mathrm{F}^{0}\left(\mathrm{~K}^{\mathrm{pax}}\right)=\frac{,\left(1_{i}^{-}\right)}{\mathrm{i}}$ with respect to $\bar{k}$; under the assumption of $k^{\text {ad }}>\bar{k}$, we obtain that $\frac{d k^{x a}}{d \bar{k}}>0$ : That is to conclude that, given $k_{0}$; if the amount of ..xed costs diminishes (i.e. $\bar{k}$ decreases), the economy can take-ox.

iii) To sum up, an economy which wants to take-ox by using knowledge technology requires thre factors :

${ }^{2}$ Large amount of initial knowledge,

2 Small ..xed costs,

${ }^{2}$ Good quality of knowledge technology.

\section{R eferences}

[1] Askenazy, Ph., and C. LeVan, 1999, A model of optimal growth strategy, J ournal of Economic Theory 85(1), 24-51. 
[2] Benhabib, J., and K. Nishimura, 1985, Competitive equilibrium cycles, J ournal of Economic Theory 35, 284-306.

[3] Cass, D., 1965, Optimal growth in an aggregative model of capital accumulation, Rewiev of Economic Studies 32, 233-240.

[4] Dechert, W.D., and K. Nishimura, 1983, A complete characterization of optimal growth paths in an aggregated model with non-concave production function, J ournal of Economic Theory 31, 332-354.

[5] Dimaria, C-H., and C. LeVan, 2001, Debt, corruption, R\&D and growth in developing countries, Macroeconomic Dynamics, forthcoming.

[6] Koopmans, T.C., 1965, On the concept of optimal economic growth, The Econometric A pproach to Development Planning, edited by North Holland.

[7] Le Van, C., Morhaim, L., and C-H. Dimaria, 2001, The discrete time version of the Romer mode, Economic Theory, forthcoming.

[8] Majumdar, M., and T. Mitra, 1982, Intertemporal Allocation with a nonconvex technology: The aggregative framework, J ournal of Economic Theory 27, 101-136.

[9] Romer, P., 1986, Increasing returns and long-run growth, J ournal of Political Economy 94, 1002-1037. 